activity, then an artificial increase in heart rate may achieve its antiarrhythmic effect by creating regular repolarization.

Ventricular ectopic activity was avoided in one patient by ventricular pacing at a similar rate to the sinus rate after more rapid atrial pacing had failed. The generation of ventricular ectopic activity in this patient may have been related to the creation of decremental block and its resultant re-entry circuits in the ischaemic His-Purkinje tissue. ${ }^{21}$ An alteration in the impulse pathway may have avoided the initiation of such block and therefore its arrhythmic consequences.

The exact time to introduce this form of therapy must be arbitrary. More recently at this hospital all patients with two cardiac arrests within 24 hours or one arrest with continued ventricular ectopic activity were paced. The ventricle is the site of choice for pacing in these patients. The instability of the pacing catheter in the atrium makes atrial pacing over days impracticable. Because ventricular ectopic activity was noted on stopping pacing during the first 72 hours in all patients, continued pacing for at least five days is now performed. Permanent pacing, however, has not been required in any of the eight survivors.

We would not advise the universal use of this method because many episodes of ventricular tachycardia are not recurrent, and it would be unjustified to use a technique which involves cardiac catheterization and inevitably some risk to the patient. Nevertheless, given the right indications, transvenous cardiac pacing can reduce the need for antiarrhythmic drugs, which themselves can precipitate ventricular tachyarrhythmias and cardiac failure. ${ }^{22-26}$ In our patients it reduced the need for D.C. shock and therefore avoided the possible myocardial damage that may result after electrical cardioversion. ${ }^{27}$ The avoidance of arrest gives the patients confidence in recovery and lightens the burden of busy medical and nursing staff.
REFERENCES

1 Sowton, E., Leatham, A., and Carson, P., Lancet, 1964, 2, 1098.

Swedberg, J., and Malm, A., Acta Chirurgica Scandinavica, 1964, 128,

${ }^{3}$ Eraklis, A. J., Green, W. T., and Watson, C. G., Annals of Surgery, $1965,161,63$.

- Heiman, D., and Helwig, J., fournal of the American Medical Association, 1966, 195, 1150.

5 Schoonmaker, F. W., Osteen, R. T., and Greenfield, J. C., Annals of Internal Medicine, 1966, 65, 1076.

- McCallister, D., McGoon, D. C., and Connolly, D. C., American fournal

- Kastor, J. A., De Sanctis, R. W., Harthorne, J. W., and Schwartz, G.,

Annals of Internal Medicine, 1967, 66, 939. Annals of Internal Medicine, 1967, 66, 945

- Lewn, H. T., and March, H. W., American Heart fournal, 1967, 73, 794.

10 Tancredi, R. G., McCallister, B. D., and Mankin, H. T., Circulation, 1967, 36, 598 . 11 Zipes, D. P., and Orgain, E. S., Annals of Internal Medicine, 1967, 67,

12 I.oeb, H. S., Pietras, R. J., Gunnar, R. M., and Tobin, J., Circulation, $1968,38,210$.

13 Zipes, D. P., et al., Annals of Internal Medicine, 1968, 68, 591.

14 Moss, A. J., Rivers, R. J., Griffith, L. S., Carmel, J., and Millard, E., New England fournal of Medicine, 1968, 278, 928 .

15 Hornbaker, J. H., Humphries, J. O., and Ross, R. S., Circulation, 1969, $39,189$.

16 Friedberg, C. K., Lyon, L. J., and Donoso, E., American Heart fournal, $1970,79,44$.

17 Bennett, M. A., and Pentecost, B. L., in preparation.

18 Han, J., and Moe, G. K., Circulation Research, 1964, 14, 44

Han, J., Garcia de Jalon, P., and Moe, G. K., Circulation Research, $1966,18,18$.

so Han, J., De Tralgia, J., Millet, D., and Moe, G., American Heart fourna!, $1966,72,632$.

21 Hoffman, B. F., and Cranefield, P. F., American fournal of Medicine, 1964, 37, 670.

22 Kayden, H. J., Progress in Cardiovascular Diseases, 1961, 3, 331.

23 Castellanos, A., and Salhanick, L., American fournal of the Medical Sciences, 1967, 253, 52.

24 Davies, P., Leak, D., and Oram, S., British Medical fournal, 1965, 2, 517.

25 Kaufmann, G., Lancet, 1968, 1, 862.

26 Nagle, R. E., and Pilcher, J., Lancet, 1968, 1, 1039.

27 I.own, B., Amarasingham, R., and Neuman, J., fournal of the American Medical Association, 1962, 182, 548.

\title{
Prostatic Contribution to Normal Serum Acid Phosphatase
}

\author{
DONALD DOW, ${ }^{*}$ F.R.C.S.ED. ; ROBERT H. WHITAKER, ${ }^{*}$ M.CHIR., F.R.C.s.
}

\author{
British Medical fournal, 1970, 4, 470-472
}

\begin{abstract}
Cummary : Total and tartrate-labile serum acid phosphatase levels were compared in patients with and without prostates, and in 12 patients before and after cystoprostatectomy. Absence of the prostate seems to make no significant difference to the levels of serum acid phosphatase. There is no justification for referring to the tartrate-labile serum acid phosphatase as "prostatic acid phosphatase." A substantial incidence of marginally raised levels of serum acid phosphatase in each group of patients suggests that the upper limit of normal for the total serum acid phosphatase should be taken as 5 K.A.u.
\end{abstract}

\section{Introduction}

The total serum acid phosphatase comprises a mixture of phosphatases from most tissues of the body (Doe and Seal, 1965). Fishman and Lerner (1953) showed that the activity of part of the total serum acid phosphatase could be inhibited by L-tartrate. The acid phosphatase found in the prostate is tartrate-inhibitable (labile), as is also a large proportion of that found in the liver, spleen, and kidneys (Abul-Fadl and King, 1949).

It is not clear what contribution the various organs make to the total serum acid phosphatase and in particular to the tartrate-labile fraction. It has generally been assumed that the prostate is the major source of the normal serum tartratelabile acid phosphatase; hence this fraction has commonly

\footnotetext{
- Resident Surgical Officer, St. Peter's Hospital, London W.C.2.
}

been referred to as the "prostatic acid phosphatase." King and Jegatheesan (1959), however, noted that the mean values of the tartrate-labile acid phosphatase are practically the same for males and females, and concluded that this "prostatic" component in normal persons must come from sites other than the prostate. It was felt that a study of a series of patients undergoing total cystoprostatectomy might shed further light on the extent to which the prostate contributes to the normal serum acid phosphatase levels.

\section{Patients and Methods}

Total serum acid phosphatase and tartrate-labile acid phosphatase levels were determined in 100 patients. Of these, 25 were men who had total cystoprostatectomy for bladder cancer, and in 12 of these the determinations were made both before and after surgery. A detailed histological examination of the excised specimen showed that none of these patients had malignancy of the prostate. There were 25 men with no symptoms of prostatic disease, and a further 25 men who had estimations before transurethral or retropubic prostatectomy for what was subsequently shown histologically to be benign prostatic hypertrophy. Finally, determinations were made on 25 women-9 were healthy volunteers and 16 were women admitted for minor endoscopic procedures. There was no history, past or present, of carcinoma of the breast in any of these women.

Throughout, the King-Armstrong (1934) method as modified by Gutman and Gutman (1940) was used, and all results are expressed as King-Armstrong units per $100 \mathrm{ml}$. of 
Ages and Acid Phosphatase Levels, expressed in King-Armstrong units, in the Four Groups of Patients

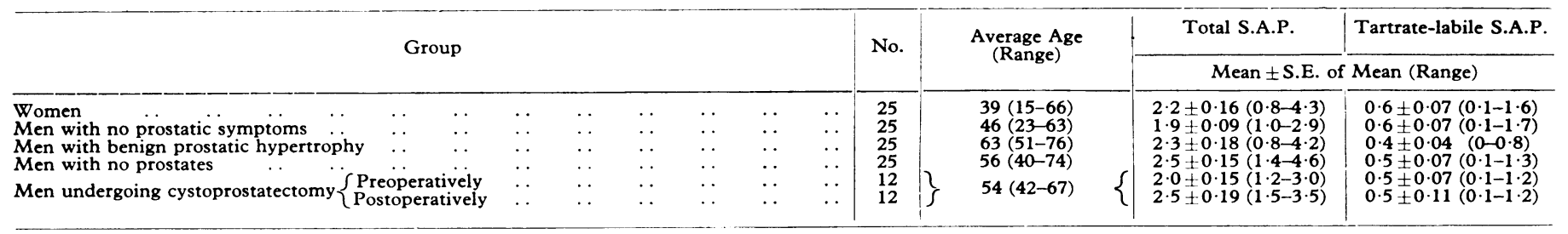

plasma. This method uses disodium phenylphosphate as the substrate, which is incubated at $\mathrm{pH} 4.9$ and a temperature of $37^{\circ} \mathrm{C}$. with the test serum. In our laboratory the period of incubation is three hours. The phosphatase hydrolyses the substrate and the released phenol is measured. The range of normal values used in different series has varied, Gu'man and Gutman (1940) giving 2 K.A.u. as the upper limit of normal for total serum acid phosphatase, while Abul-Fadl and King (1948) suggested an upper value of 5 K.A.u. Similarly, laboratories vary in their upper normal for serum acid phosphatase, taking values from 3 to 5 K.A.u. Normal tartrate-labile serum acid phosphatase is generally accepted as not exceeding $0.8 \mathrm{~K}$.A.u. Our laboratory takes $1 \cdot 2-3 \cdot 1$ K.A.u. as the range of the total serum acid phosphatase and 0-0.8 K.A.u. for the tartrate-labile fraction. These ranges allow for two standard deviations from the mean. No estimations were made after rectal examination, instrumentation, or within three weeks after operation.

\section{Results}

The serum acid phosphatase levels in the four groups of patients are shown in the Table. There is no statistically significant difference in the levels, either total or tartrate-labile, when the women are compared with either all the 75 men or with the separate groups of 50 men with and 25 men without prostates (Student's $t$ test).

The 25 men without prostates have statistically no less total or tartrate-labile serum acid phosphatase than the 50 men with either no prostatic symptoms or with benign prostatic hypertrophy when compared either together or separately. There was no significant difference in total and tartrate-labile levels before and after operation in the 12 patients who had total cystoprostatectomy (see Table).

Ten of the 100 patients had total levels above the accepted upper limit; three of these were women and four were men without prostates. Similarly, 14 of the 100 patients had marginally raised tartrate-labile levels, five of whom were women and five were men without prostates.

\section{Discussion}

These results suggest that the non-cancerous prostate contributes little to the level of serum acid phosphatase either total or tartrate-labile. Thus firstly we have confirmed the findings of King and Jegatheesan (1959) that the normal serum acid phosphatase levels are similar in men and women. Secondly, in men with no prostates we found an amount of tartrate-labile serum acid phosphatase similar to that found in the normal adult male. Both of these results indicate sources other than the prostate for the normal serum acid phosphatase. It is thus inaccurate and misleading to refer to the normal tartrate-labile fraction of serum acid phosphatase as "prostatic acid phosphatase."

Undoubtedly, measurement of serum acid phosphatase may be of clinical value. Patients with metastases from prostatic cancer or with extensive local growth may have persistently and grossly raised levels of both total and tartrate-labile serum acid phosphatase. This is of diagnostic value, and subsequent measurements reflect the effectiveness of treatment. Cook et al. (1962) pointed out that the bulk of the abnormal serum acid phosphatase found in patients with metastasizing prostatic cancer consisted of tartrate-labile serum acid phosphatase. The relation between total and tartrate-labile serum acid phosphatase found in our last 23 estimations where the total serum acid phosphatase exceeded 5 K.A.u. is shown in the Chart. Clearly in grossly raised levels the rise in tartratelabile serum acid phosphatase parallels the rise in total serum acid phosphatase. Thus in patients suspected of having prostatic malignancy it is debatable whether it is necessary to measure the tartrate-labile fraction in the presence of a grossly raised total serum acid phosphatase. Doubts concerning the value of the tartrate-labile fraction have been raised before (Peterson, 1961).

Marginally raised levels should be interpreted with caution as 10 and $14 \%$ of patients in the present series have marginally raised levels of total and tartrate-labile serum acid phosphatase respectively. These findings agree with those of Cook et al. (1962), who found that $8.3 \%$ of a large series of patients without prostatic malignancy had marginally raised tartrate-labile serum acid phosphatase levels. Therefore it is suggested that only persistent levels of serum acid phosphatase above 5 K.A.u. and of tartrate-labile serum acid phosphatase above 2 K.A.u. should be taken as definitely raised and suggestive of prostatic disease. A rise of total serum acid phosphatase of between 3.5 and 5 K.A.u. and of tartratelabile serum acid phosphatase between 0.8 and 2 K.A.u. may arouse suspicion, particularly if the rise is persistent, but by itself does not indicate the presence of prostatic cancer and is not sufficient proof for starting the patient on oestrogens.

It is difficult to recommend that the estimation of serum acid phosphatase be abandoned, as under the circumstances mentioned previously it can be of value in managing the patient with established carcinoma of the prostate. Of all the biochemical investigations commonly performed, however, it must be one of the poorest screening tests and must represent a considerable waste of time and energy in most laboratories. The tartrate-labile serum acid phosphatase seldom gives additional information to the total serum acid phosphatase.

We are grateful to the surgeons of the St. Peter's Group of Hospitals for allowing us to study patients under their care and to Dr. G. A. Rose for his advice in the preparation of this paper. We

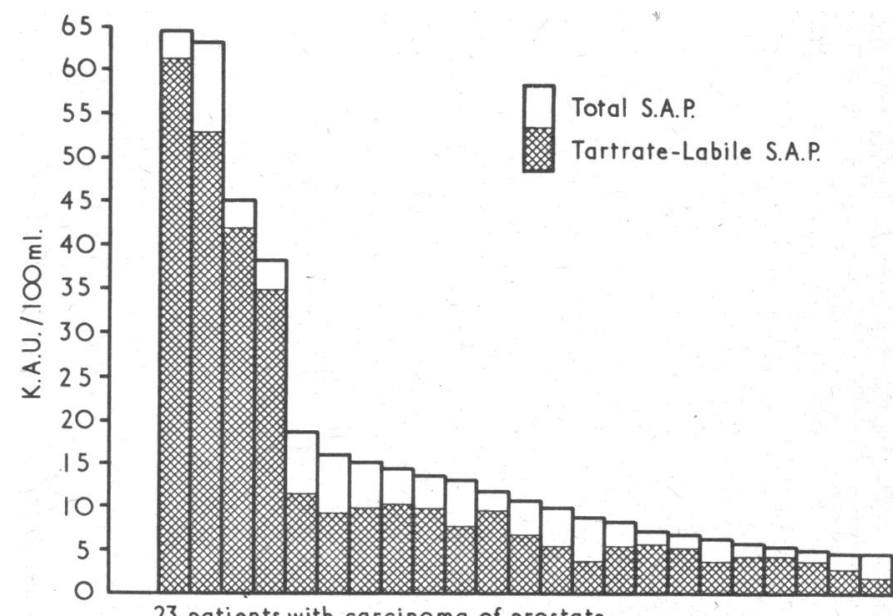

23 patients with carcinoma of prostate

Relationship between the total and tartrate-labile serum acid phosphatase in 23 patients who were known to have carcinoma of the prostate and whose total serum acid phosphatase was over 5 K.A.u. 
wish to thank the members of the St. Paul's Hospital Biochemistry Laboratory who performed all the acid phosphatase determinations, and the departments of medical illustration and photography for the preparation of the Chart.

REFERENCES

Abul-Fadl, M. A. M., and King, E. J. (1949). Biochemical fournal, 45, 51. Cook, W. B., Fishman, W. H., and Clarke, B. G. (1962). Journal of Urology, 88,281 .
Doe, R. P., and Seal, U. S. (1965). Surgical Clinics of North America, 45, 1455. Fishman, W. H., and Lerner, F. (1953). Fournal of Biological Chemistry, 200,89 .

Gutman, E. B., and Gutman, A. B. (1940). Fournal of Biological Chemistry, 136, 201.

King, E. J., and Armstrong, A. R. (1934). Canadian Medical Association fournal, 31, 376.

King, E. J., and Jegatheesan, K. A. (1959). Fournal of Clinical Pathology,

Peterson, C. G. (1961). Fournal of Urology, 85, 643.

\section{Preliminary Communications}

\section{Endotoxin and Acute Renal Failure Associated with Obstructive Jaundice}

\author{
British Medical fournal, 1970, 4, 472-474
}

\begin{abstract}
Qummary: A single dose of endotoxin given to rats with obstructive jaundice produced death with intravascular coagulation. This action was apparently due to delayed clearance of endotoxin from the circulation. The finding is relevant to "hepatorenal failure," which can be caused by bacteraemia after biliary tract operations.
\end{abstract}

\section{INTRODUCTION}

About $12 \%$ of patients who undergo operations for biliary tract disease develop acute renal failure (Funck-Brentano, Méry, Vantelon, and Watchi, 1963). Morphological changes range from mild to severe tubular necrosis (Bloodworth and Sommers, 1959) but occasional patients have renal cortical necrosis. Most clinicians agree that a Gram-negative septicaemia often follows such surgery (Caroli, 1958; Crosnier, 1958; Hamburger, 1958; Hepp, 1958), so that some cases of acute renal failure with obstructive jaundice could be the result of endotoxic shock. Such cases would be the human equivalent of a Shwartzman reaction (Hjort and Rapaport, 1965), and this concept is particularly relevant to the development of cortical necrosis (Vassalli and Richet, 1961).

We noticed that a single dose of endotoxin given to the rat with obstructive jaundice usually caused death with much fibrin deposition in the renal vasculature. Investigation shows that the clearance of endotoxin from the blood stream is delayed in the presence of obstructive jaundice. Endotoxin is normally removed from the blood by the phagocytic cells of the liver and spleen (Braude, Carey, and Zalesky, 1955).

\section{METHODS}

Obstructive jaundice was produced in the rat by tying the common bile duct just before entry into the duodenum. Three days later these rats and appropriate controls were given Escherichia coli endotoxin 0127.B8 (Difco) by intravenous injection in a dose of $100 \mu \mathrm{g} . / 100 \mathrm{~g}$. body weight. This is a large dose of endotoxin. Coagulation studies included the measurement of prothrombin time and the thrombin-clotting time, the platelet count, and the plasma fibrinogen, together with fibrin monomer. Fibrin monomer is the initial hydrolytic product of the action of thrombin on fibrinogen-that is, fibrinogen with peptides $A$ and $B$ removed-and is normally polymerized by the fibrin-stabilizing factor. Fibrin monomer can be estimated by aggregation with protamine sulphate (Lipiński and Warowski, 1968).

Rats given rat fibrinogen prepared and labelled with 131-iodine by the method of McFarlane (Campbell et al., 1956) were studied. The half-life of the labelled fibrinogen and the shape of the disappearance curve were determined from serial plasma fibrinogen counts. In interpreting the curves of plasma fibrinogen survival it should be noted that a large dose of thromboplastin causes "absolute defibrination" with a profound permanent loss of labelled fibrinogen, but a small dose can cause "rebound defibrination," in which, after an immediate depletion of labelled fibrinogen, from the intravascular pool, there is a later reappearance of labelled material (Adelson, 1968). This further fibrinogen probably returns from the extravascular space by way of the lymphatics (E. N. Wardle, unpublished observations).

Studies were performed on groups of four rats, two normal and two with jaundice. On the third day of the study they were given the intravenous endotoxin. Some also received intravenous Isothrodym (neodym-3-sulpho-isonicotinate) at a dose of $50 \mathrm{mg} . / \mathrm{kg}$. weight. This rare earth metal derivative was originally found to have an anticoagulant action, but is now known to produce reticuloendothelial blockade (Lázár, Karády, and Husztik, 1969) and to enhance intravascular coagulation (Lázár and Karády, 1965). In further studies the clearance of chromium-labelled endotoxin (Herring, Herion, Walker, and Palmer, 1963) or of microaggregated 131-iodinelabelled human albumin (Shaldon, Chiandussi, Guevara, Caesar, and Sherlock, 1961) was determined by collecting timed samples from the rat tail vein at intervals after intravenous injection. Microaggregated albumin was used in a dose of $0.5 \mathrm{mg} . / 100 \mathrm{~g}$. body weight (Benacerraf, Biozzi, Halpern, Stiffel, and Mouton, 1957), and for each batch normal clearance times were determined. Histological sections were stained with haematoxylin and eosin and Martius scarlet-blue for fibrin (Lendrum, Fraser, Slidders, and Henderson, 1962).

\section{RESULTS}

Of animals with obstructive jaundice given a single dose of endotoxin 18 out of 20 animals died, whereas only 2 out of 10 normal animals died. Those animals which died did so within a period of four to six hours.

A synopsis of the coagulation studies is given in Table I, where mean values for six pairs of animals before and after the injection of a single dose of endotoxin are given. Blood samples were collected 10 minutes after the dose, either from the tail vein or by cardiac puncture.

The results of the radioactive fibrinogen catabolism studies are shown in the Chart. One-third of the animals with jaundice given a single dose of endotoxin showed "rebound defibrination." In about another third there appeared to be "absolute defibrination," but death was sometimes too early to allow for serial specimens. Animals with obstructive jaun-

TABLE I.-Coagulation Studies before and after a Single Dose of Endotoxin

\begin{tabular}{|c|c|c|c|c|}
\hline & \multicolumn{2}{|c|}{ Normal Animals } & \multicolumn{2}{|c|}{ Obstructive Jaundice } \\
\hline & Before & After & Before & After \\
\hline 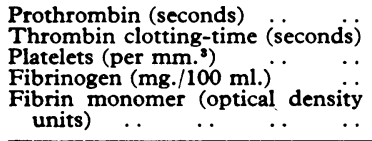 & $\begin{array}{c}10 \cdot 0 \\
5 \cdot 0 \\
390,000 \\
290 \\
0 \cdot 14\end{array}$ & $\begin{array}{c}90 \cdot 0 \\
7 \cdot 0 \\
350,000 \\
260 \\
0 \cdot 12\end{array}$ & $\begin{array}{c}120 \\
3 \cdot 0 \\
380,000 \\
400 \\
0 \cdot 105\end{array}$ & $\begin{array}{c}300 \\
30 \cdot 0 \\
160,000 \\
300 \\
0 \cdot 105\end{array}$ \\
\hline Fibrinogen half-life (hours) & \multicolumn{2}{|c|}{$20-40$} & \multicolumn{2}{|c|}{$18 \cdot 0-30 \cdot 0$} \\
\hline
\end{tabular}

Mean values for six pairs of animals. 